1 RUNNING HEAD: Youth Sport

2

3

4

\title{
Evidence-based policies for youth sport programs
}

5

Submitted to: International Journal of Sport Policy \& Politics

7

Date: October 30, 2013

8

Revised: February 11, 2014

9

Second Revision: April 15, 2014

10

11

12

13

14

15

16

17

18

19

20

21

22 Key Words: Youth, participation, performance, personal development 


\section{Abstract}

2 Youth sport involvement can lead to outcomes classified as the 3Ps: performance,

3 participation, and personal development (Côté et al. 2007a). The 3Ps are central to

4 youth sport systems aimed at providing quality experiences to participants. A challenge

5 for countries and national governing bodies is structuring sport to simultaneously

6 facilitate the achievement of excellence and participation (Collins 2010), or the 3Ps. To

7 illustrate this challenge, consider deliberate practice, which is an important activity for

8 performance improvements, but also considered less enjoyable and less motivating

9 compared to other sport activities, such as play (Ericsson et al. 1993). Thus, governing

10 bodies often face the challenge of deciding which activities they intend to emphasize

11 (e.g., early specialization directed at talent development or early diversification aimed at

12 increasing participation), and this can have implications for the success/failure of the

13 3Ps. The purpose of this article is to describe an inclusive sport structure for children

14 (under age 13) targeting the development of the 3Ps, which would be an asset to sport

15 scientists, policy makers, and practitioners. Common goals for the 3Ps include: avoid

16 burnout/dropout, cultivate intrinsic motivation, and maximize involvement in various

17 sport activities. Our contention is the 3Ps can co-exist under one system when that

18 system is structured according to the age and competitive level of participants. The

19 Developmental Model of Sport Participation (Côté and Abernethy 2012) and its 7

20 postulates (Côté et al. 2009) will be used as the basis of this paper to provide evidence-

21 based policies for children in sport. 
1 Youth sport has the potential to promote a number of important outcomes in

2 young people's development. From a policy perspective, authors (e.g., Skille 2011,

3 Comeau 2013) have discussed two views of youth sport that are often perceived as being

4 contradictory: excellence and participation. Despite the promotion of these two

5 objectives, it appears that the elite youth sport agenda typically comes ahead of the

6 participation objectives and that few countries are able to balance policies and resources

7 that maximize the developmental benefits of youth sport (Collins 2010). Nevertheless,

8 Skille (2011) highlighted the limitation of policy analysis of national sport systems and

9 suggested a bottom up approach for research that focuses on particular sport clubs and

10 athletes to better understand how individuals achieved various outcomes in sport. The

11 questions surrounding "What constitutes the outcomes of youth sport?" and "How are

12 these outcomes achieved?” are issues that coaches, parents, and policy makers struggle

13 to define and agree upon (Coalter 2007). These fundamental questions have created

14 several debates among researchers and policy makers in terms of how youth sport

15 programs should be structured.

16 Siedentop (2002a), for example, suggested three primary goals for junior youth

17 sport programs: the elite-development goal, the public health goal, and the educative

18 goal. Similarly, Côté et al. (2007a) refer to the outcomes of youth sport as the 3 Ps:

19 Performance, Participation, and Personal Development. Accordingly, there is evidence

20 from research and practice that different youth sport programs are structured to meet

21 these outcomes independently. For instance, a number of researchers view youth sport

22 as the initial step in talent development programs that are aimed at developing the

23 performance of elite level athletes (e.g., Ford et al. 2009). Such programs are 
1 characterized by the long-term goal of achieving elite performance; unfortunately, this is

2 often at the cost of short-term gratification and enjoyment (Côté and Abernethy 2012).

3 Other researchers advocate that youth sport programs should maximize time spent in

4 physical activity as a way to diminish issues related to lack of exercise among youth

5 (e.g., Janssen and LeBlanc 2010). Accordingly, several youth sport programs have been

6 developed with the goal of increasing physical activity participation through sport

7 (Siedentop 2002b). Finally, numerous researchers propose that sport is an ideal activity

8 to teach and transmit positive life values to young people (e.g., Danish et al. 1993).

9 Several sport programs, such as Sports United to Promote Education and Recreation

10 (SUPER; Danish et al. 2002), Play it Smart (Petitpas et al. 2004), and the First Tee

11 (Weiss et al. 2013) are specifically designed to achieve this objective of facilitating

12 personal development through sport. These examples of programs are in line with

13 different views of youth sport as having the power to enhance physical activity

14 participation, elite performance, and development; however, the focus of programs on

15 one outcome over another creates difficulty for policy makers (Coalter 2010).

16 The challenging task of policy makers and administrators of youth sport

17 programs is to develop a structure that meets the multiple needs of young participants

18 and serves the different outcomes of youth sport. Siedentop (2002a) has suggested that

19 the contrasting natures of the different outcomes of youth sport are not achievable within

20 single program and should be promoted by different programs:

21 Goals for sport programs, of course, don't have to be mutually exclusive,

22 and one is tempted to argue that all goals can be met equally through one

23 system; but that smacks of theology rather than theory, and the evidence 
1 doesn't support that particular theology (p. 394)

2 Evidence has accumulated since this statement and one can make a defensible argument

3 that the outcomes of performance, participation, and personal development are not

4 necessarily incompatible. In this article, we present a global picture of sport policy in

5 youth sport - one which focuses on developing all of the 3Ps - that is clearly supported

6 by scientific evidence and can be implemented by regional and national sport governing

7 bodies. We will first discuss the three general outcomes of youth sport and present

8 research that supports the design of sport programs during childhood that positively

9 impact the participation rate, future elite performance, and personal development of 10 youth athletes.

11

\section{Performance}

Early specialization programs where children are identified and selected at a young age to compete and achieve at an elite level of performance are common in several countries around the world and in various sports. For instance, competitive gymnastics programs, tennis academies, or elite soccer clubs identify children at young ages to put them through rigorous training programs with the long-term goal of developing elite athletes. The human and physical resources invested in these programs are important as youth are seen as raw potential that need to be developed. As an example, Pearson et al. (2006) reported that professional sports clubs in England continue to invest substantial resources into attempts to identify talented athletes at young ages.

Reviews of the talent detection and identification literature in sport, however, show that long-term prediction of talented athletes is unreliable, especially when detection of talent is attempted during the prepubertal or pubertal growth periods (e.g., 
1 Vaeyens et al. 2009). One study that particularly exemplifies the difficulty of talent

2 detection and prediction was conducted with ice hockey players in Canada. Parcels

3 (2002) described the chances of achieving elite status in ice hockey (i.e., playing in the

4 National Hockey League [NHL]), noting that transition from youth ice hockey to the

5 NHL is extremely rare. 33,000 males born in 1975 registered with the Ontario Minor

6 Hockey Association, a youth developmental league. From this cohort, 48 (0.15\%) were

7 eventually drafted by an NHL team, though only 32 (0.09\%) played one NHL game.

8 Even more rare were players that played more than one full NHL season (15; 0.04\%)

9 and players that played over 400 games, or approximately five seasons (6; 0.01\%). With

10 such low odds for success, it is understandable that predicting elite status in youth sport

11 is unreliable.

12 Ericsson et al. (1993) framework of deliberate practice (defined as high quality,

13 high concentration practice that is not inherently enjoyable and done with the primary

14 goal of improving performance) suggests a performance approach to youth sport

15 programming. The deliberate practice framework, which has been popularized in books

16 such as Outliers (Gladwell 2008) and the Talent Code (Coyle 2009), suggests that to

17 reach the highest level of performance, one must engage in 10,000 hours or 10 years of

18 deliberate practice in their chosen domain (sport). Essentially, the framework proposes

19 that elite athletes must specialize in their main sport and start deliberate practice at a

20 very young age.

21 While there is some sport research that supports a positive relationship between

22 deliberate practice training and elite performance (e.g., Hodges and Starkes 1996,

23 Starkes et al. 1996, Helsen et al. 1998, Hodge and Deakin 1998), several dimensions of 
1 the theory of deliberate practice have not been supported (see Abernethy et al. 2003 for

2 a review). For example, few studies have shown that 10,000 hours of deliberate practice

3 is indeed a prerequisite for expert performance in sport. To the contrary, studies show

4 that expert performance in sports where peak performance generally occurs after the age

5 of 20 has been achieved with 3,000 to 4,000 hours of sport-specific training (i.e.,

6 deliberate practice; Côté and Abernethy 2012). Therefore, specialized sport programs at

7 young ages (i.e., ages 6-12) to develop elite level athletes are not necessary in most

8 sports. Instead, providing opportunities for all children to participate in various informal

9 and organized recreational sports should be the focus of sport programmers even if

10 developing elite athletes (e.g., the performance objective) is the ultimate goal of the

11 program. In other words, diversity (instead of specialization) during childhood has a

12 positive effect on future elite performance as well as long-term participation in sport

13 (Côté et al. 2009).

14

\section{Participation}

Recreational sport programs that supposedly focus on involvement of all youth are among the most popular extra-curricular activities for children. Recently, ESPN collated a wealth of information from previous research on recreational sport participation in the United States (Kelley and Carchia 2013). This allowed ESPN to present a comprehensive examination of youth sport participation rates and influences on sport participation. The study affirmed the popularity of youth sport, noting that 25 million youth (aged 6-17) participated in some form of recreational sport during the previous year. Examining these numbers further, approximately $60 \%$ of male youth and $50 \%$ of female youth were registered on at least one organized sport team by age 6 . 
1 Although recreational youth sport programs should lead to lifelong participation in

2 sport, the dropout rate during adolescence is alarming with an estimated one-third of all

3 participants between 10 and 17 years of age withdrawing from sport programs every

4 year (Gould 1987, Kelley and Carchia 2013).

While youth sport clearly provides opportunities for long-term participation,

6 there appears to be a void between the potential of youth sport and some of the negative

7 realities of youth sport programs, as evidenced by the dropout rate. One of the key

8 issues for researchers and practitioners must be to close this void and work together to

9 assure that youth have positive rather than negative experiences in sport, thereby

10 reducing the dropout rate and sustaining long-term participation. The potential financial

11 and social rewards that can result from participation in elite sport as adults, have

12 affected youth sport programming over the last 20 years. Youth sport programs around

13 the world are adapting a view of sport that focuses on long-term athlete development,

14 institutionalization, elitism, early selection, and early specialization with the explicit or

15 implicit goal of developing elite level athletes (Collins 2010, Côté et al. 2011) instead of

16 focusing on the short-term and inherent enjoyment that result from sport participation.

17 Today's recreational sport programs supervised by adults are requiring higher levels of

18 investment from earlier ages (Ewing and Seefeldt 1996, Hancock et al. 2013a), and

19 focus on certain aspects of sport participation (e.g., development of skills) that often do

20 not coincide with children's motives to participate in sport in the first place (e.g., have

21 fun and be with friends). In other words, these types of recreational programs often

22 discourage children from participating in a diversity of activities that are instantly

23 rewarding and enjoyable. However, there seems to be clear evidence suggesting that 
1 sport programs such as these may not be providing optimal environments for youths'

2 long-term participation in sport and, as importantly, hinder overall physical and

3 psychosocial development (Côté et al. 2011).

4

5

6 development such as First Tee (Weiss et al. 2013), Teaching Personal and Social

$7 \quad$ Responsibility in sport program (TPSR; Hellion and Walsh 2002), and Sports United to

8 Promote Education and Recreation program (SUPER; Danish et al. 2002). In such

9 programs, athletes learn about personal development assets, such as goal setting or

10 perseverance, and are explicitly taught to transfer such assets to other life settings (e.g.,

11 goal setting in educational environments). However, if sport is only perceived as a

12 support for personal development in other domains, there is a risk to undermining the

13 value of sport-specific knowledge and skills also beneficial to long-term sport

14 participation (Turnnidge et al. in press). A sole focus of sport programs on personal

15 development is an adult decision that does not necessarily align with children's

16 motivation to participate in sport.

17

18 the inherent value of sport participation and the best way to transmit positive personal

19 values through sport. The advantage of a diversified and playful environment in sport

20 during childhood is that it provides young athletes with a breadth of experiences that

21 emphasize exploration before commitment to a specific sport activity. Empirical

22 evidence (Busseri et al. 2006, Fredericks and Eccles 2006, Rose-Krasnor et al. 2006)

23 shows that a breadth of experiences in early development is an indicator of continued 
1 involvement in more intense activities later in life and of successful development of

2 personal assets such as competence and confidence. Furthermore, youth sport programs

3 built around the concepts of diversity and play have a protective effect against negative

4 outcomes such as burnout, dropout, and injuries (Law et al. 2007, Wall and Côté 2007,

5 Fraser-Thomas et al. 2008a, 2008b).

6 The experiences and opportunities that sport provides are not different from

7 other life situations and, therefore, it is reasonable to assume that a positive environment

8 is the best way to promote positive youth development through sport participation.

9 Accordingly, the eight setting features of the National Research Council and Institute of

10 Medicine (NRCIM; 2002) have received increasing support from youth sport research as

11 they offer an additional understanding of the context in which youth sport should be

12 structured to promote personal development (Strachan et al. 2011). The eight setting

13 features of the NRCIM are consistent with models of development in sport that favour

14 play and inclusion (e.g., Siedentop 2002a, Griffin and Butler 2005, MacDonald et al.

15 2009) to promote the outcomes of excellence and participation in sport.

16 Integration of Performance, Participation and Personal Development

17 Although it is relatively easy to identify the primary objective of a given youth

18 sport program, a sole focus on one objective (e.g., performance) often reduces the

19 importance of the other two objectives (e.g., participation and personal development) and

20 minimizes the potential that sport involvement can have on youths' lives. There is growing

21 evidence that youth sport programs for children can be designed to focus on all three

22 outcomes and be successful in developing skilled performance, maintaining participation

23 rates, and enhancing personal development. Thus, by focusing on the common building 
1 blocks that all young people need, we can enhance the experience of children in sport and

2 reduce the costs associated with the design of different youth sport programs.

3 Understanding athlete development models is the first step in this process.

4 Athlete Development Models

$5 \quad$ Over the past three decades, a number of athlete development models have been

6 proposed. Alfermann and Stambulova (2007) highlighted and reviewed five of these

7 research-based models (Bloom 1985, Salmela 1994, Stambulova 1994, Côté 1999,

$8 \quad$ Wylleman and Lavallee 2004). More recently, Bruner et al. (2010) conducted a citation

9 network analysis and revealed two additional models published in peer-reviewed

10 journals (Abbott and Collins 2004, Bailey and Morley 2006). Surprisingly, the Long-

11 Term Athlete Development model (LTAD; Balyi and Hamilton 2004) did not appear in

12 these comprehensive reviews despite its widespread implementation in many countries.

13 The lack of research around the LTAD reinforces its focus as a commercial product that

14 is not supported by any significant line of evidence. In fact the LTAD was originally

15 developed as an elite performance model based on principles of motor development and

16 has been adjusted over the years to fit the agenda of various sport organizations and

17 government policies. The most recent version of the LTAD contains numerous claims

18 about athletes' development that are often conflicting and have never been tested or

19 evaluated in specific sport contexts (Bailey et al. 2010, Ford et al. 2011, Malina 2013).

20 Citation analysis studies of athletes’ developmental models (Bruner et al. 2009,

21 Bruner et al. 2010) have found the Developmental Model of Sport Participation

22 (DMSP; Côté 1999, Côté et al. 2007b) to be the most prominent conceptualization of

23 athletes' development in the sport literature. The DMSP has been developed and 
1 refined over the last 20 years and presents a set of concepts about athletes' development

2 that are quantifiable and testable. The DMSP was developed in a series of four steps

3 that must be understood before the model is applied to the 3Ps of sport outcomes.

4 The first step involved an initial conceptualization of athletes' development

5 resulting from interviews with parents, coaches, and athletes (Côté 1999). This original

6 model was in line with results from other qualitative studies of athletes' development (e.g.,

$7 \quad$ Bloom 1985, Carlson 1988) while providing explicit and original propositions that could

8 be quantified and tested empirically. Two new concepts regarding sport involvement

9 throughout the lifespan emerged from this first step: 1) diversity and 2) deliberate play.

10 The concept of diversity describes a level of involvement in different sports during

11 childhood. Indeed, retrospective studies of elite athletes in different sports and from

12 different backgrounds support the idea that being involved in different sports during

13 childhood is linked to long-term participation and elite performance in sport (Berry et al.

14 2008, Gulbin et al. 2010, Leite and Sampaio 2012, Bridge and Toms 2013). The concept

15 of deliberate play was described by elite level athletes (Côté 1999) as sport activities they

16 engaged in during childhood that were inherently enjoyable and differed from organized

17 sport and adult-led practices such as deliberate practice. Activities that exemplify

18 deliberate play include street hockey and pick-up basketball. These games use adapted

19 rules of traditional sports (e.g., one-on-one basketball) and are loosely monitored by the

20 children playing the sport and/or adults. Deliberate practice, on the other hand, requires

21 effort, generates no immediate rewards, and is motivated by the goal of improving

22 performance rather than its inherent enjoyment (Ericsson et al. 1993). The concepts of

23 diversity and deliberate play were the main elements of the proposed DMSP, which 
1 consisted of three stages of development including the 1) sampling years (ages 6-12), 2)

2 specializing years (ages 13-15), and 3) investment years (ages 16+).

In a second step, a quantitative, retrospective methodology was developed over

4 several years (Côté et al. 2005) to test the assumptions of the DMSP. More specifically,

5 the retrospective interview was designed to account for the developmental activities of

6 athletes throughout the three stages of the DMSP, and to test the importance of

7 diversification versus specialization and deliberate play versus deliberate practice

8 throughout the athletes' careers. Using this methodology, a series of studies were

9 conducted with groups of expert and non-expert athletes (e.g., Baker et al. 2003a, Baker et

10 al. 2003b, Soberlak and Côté 2003, Baker et al. 2005, Law et al. 2007, Berry et al. 2008)

11 to refine the DMSP and provide clarity on its different outcomes and trajectories. All in

12 all, these studies showed that diversity and deliberate play during childhood are important

13 developmental activities associated with expertise (performance) and long-term sport

14 retention (participation). Transitioning to the specialization stages in one or two sports,

15 accompanied by higher amounts of deliberate practice, usually occurred after age 13 . This

16 was followed two to three years later by high investment and high deliberate practice in

17 one sport. These findings are consistent across sports where peak performance is achieved

18 after maturity such as ice hockey, baseball, rowing, and triathlon, but does not hold for

19 sports in which peak performance is achieved during adolescence, such as gymnastics

20 (Law et al. 2007). Following this knowledge accruement, the DMSP was adapted to

21 reflect the different developmental trajectories. A new "early specialization” pathway was

22 added to the DMSP to parallel the three-stage model of sampling, specializing, and

23 investment. Additionally, a "recreational participation" stage was added to reflect the 
1 choice that athletes can make after the sampling years; that is, to move into a recreational

2 or a specialization stage of participation. 17 learning.
For the third step in the DMSP refinement, the retrospective method was adapted and used to compare the activities, experiences, and outcomes of athletes that engaged in different pathways of the DMSP (Robertson-Wilson et al. 2003, Wright and Côté 2003, Wall and Côté 2007, Fraser-Thomas et al. 2008a, Strachan et al. 2009). This holistic approach to athletes' development was further substantiated with new qualitative studies of athletes who had achieved long-term participation and exceptional performance in sport (Fraser-Thomas and Côté 2009, Strachan et al. 2011). Côté and Abernethy (2012) reviewed and discussed the results of this third wave of studies in a recent book chapter, and highlighted the benefits of diversification and deliberate play, as well as the costs associated with an early specialization trajectory in sport. The benefits of diversification and deliberate play consist mainly of protecting against sport attrition by reducing burnout, limiting overuse injuries, and increasing enjoyment, while early specialization increases burnout, increases overuse injuries, and reduces enjoyment. Furthermore, diversification and deliberate play can make unique contributions to skill development through implicit

Finally, a fourth step involved the refinement of the DMSP by making specific links between the different pathways and the outcomes of performance, participation, and personal development. This stage involved mainly the writing of theoretical papers (Fraser-Thomas et al. 2005, Côté et al. 2007a, 2007b) and the creation of seven postulates related to the concepts of diversity and deliberate play during childhood (Côté 2009, Côté et al. 2009). Below is the updated evidence that supports the postulates of the DMSP. 
Youth Sport -15

1 Postulate 1: Early diversification does not hinder elite sport participation in sports

2 where peak performance is reached after maturation

This postulate focuses on the association between early diversification and the

4 performance outcome of youth sport. Evidence from several studies suggests that elite

5 athletes who experience a diversified sport background can still reach an elite level of

6 performance (Bloom 1985, Carlson 1988, Baker et al. 2003b, Abernethy et al. 2005) and,

7 indeed, for some team ball sports, diversity of experience seems to be more prevalent

8 among the more successful athletes (Baker et al. 2003b, Berry and Abernethy 2009).

9 Further, the link between early diversification and performance has been established across

10 contexts including different countries (e.g., Berry et al. 2008, Bridge and Toms 2013) and

11 city sizes (Surya et al. 2012).

12 Postulate 2: Early diversification is linked to a longer sport career and has positive

13 implications for long-term sport involvement

14 This postulate focuses on the association between diversification and the

15 participation outcome of youth sport. The physical and psychological benefits of varied

16 involvement in sports on long-term participation have been supported through numerous

17 studies. Among these, evidence supports the notion that increased sport diversification

18 increases participation (i.e., avoids dropout) in many sports including tennis (Carlson

19 1988, Gould et al. 1996), swimming (Fraser-Thomas et al. 2008a, 2008b), and ice

20 hockey (Wall and Côté 2007). Additionally, longitudinal data of nine active and nine

21 inactive women over 13 years of sport participation showed that being involved in

22 various sports during childhood led to life-long participation (Robertson-Wilson et al.

23 2003). 
1 Postulate 3: Early diversification allows participation in a range of contexts that

2 most favourably affects positive youth development

This postulate focuses on the association between diversification and the

4 personal development outcome of youth sport. The advantage of a diversified

5 foundation in sport during the sampling years provides young athletes with a breadth of

6 experiences without an intense focus on skill acquisition and performance in one sport.

7 Empirical evidence (Busseri et al. 2006, Fredericks and Eccles 2006, Rose-Krasnor et al.

8 2006) shows that a breadth of experiences in early development is an indicator of

9 continued involvement in more intense activities later in life and of successful

10 development. In sport, Wright and Côté (2003) showed that diversified sport

11 experiences in childhood fostered positive peer relationships and leadership skills.

12 Wilkes and Côté (2007) reviewed the youth sport literature and suggested that

13 children who sampled a variety of sports were also exposed to unique socialization

14 experiences that shaped development. The following are five developmental outcomes

15 that sampling can promote: 1) intrapersonal skills, 2) prosocial behaviour, 3) healthy

16 identity, 4) diverse peer groups, and 5) social capital.

17 Postulate 4: High amounts of deliberate play during the sampling years builds a

18 solid foundation of intrinsic motivation through involvement in activities that are

19 enjoyable and promote intrinsic regulation

20 This postulate focuses on the association between deliberate play and the

21 participation outcome of youth sport. Motivation theories such as self-determination

22 theory (Deci and Ryan 1985, Ryan and Deci 2000) and achievement goal theory (Biddle

23 2001, Treasure 2001) suggest that early intrinsically motivating activities such as 
1 deliberate play will have a positive effect over time on an individual's overall

2 motivation. This early motivation has important implications for future development

3 and continued participation in sport. Fry (2001) notes that an individual's motivational

4 orientation appears to be set by age 12 or 13 . In order to promote lifelong, intrinsically

5 motivated sport participation, it is imperative to build a foundation during childhood.

6 Inclusion of high amounts of deliberate play activities early in development provides

7 that motivational foundation. Support for this postulate has emerged from qualitative

8 studies of athletes’ careers (e.g., Bloom 1985, Carlson 1988, Côté 1999) and from

9 quantitative studies of expert and non-expert athletes' training and experiences (e.g.,

10 Baker et al. 2003a, 2003b, Soberlak and Côté 2003, Baker et al. 2005, Berry et al. 2008).

11 Furthermore, studies of dropout athletes provide additional evidence that deliberate play

12 during childhood is an important determinant of continued participation and

13 commitment to sport (Wall and Côté 2007, Fraser-Thomas et al. 2008a, Fraser-Thomas

14 and Côté 2009).

15 Postulate 5: A high amount of deliberate play during the sampling years establishes

16 a range of motor and cognitive experiences that children can ultimately bring to

17 their principal sport of interest

18 This postulate focuses on the association between deliberate play and the

19 performance outcome of youth sport. Qualitative and quantitative studies have

20 demonstrated that high amounts of deliberate play in elite tennis (Carlson 1988, Côté

21 1999), rowing (Côté 1999), ice hockey (Soberlak and Côté 2003) and baseball (Hill

22 1993) were associated with elite performance in adulthood. Furthermore, quantitative

23 comparisons of elite and less elite athletes demonstrated that elite players were involved 
1 in more deliberate play hours than deliberate practice hours during childhood (Berry et

2 al. 2008, Memmert et al. 2010, Ford and Williams 2012). The development of

3 adaptability and creativity promoted by free experimentation in a safe, low-risk

4 environment has been posited as the mechanism accounting for the empirically recorded

5 benefits of deliberate play activities on skill acquisition and elite performance (Côté et

6 al. 2007b).

$7 \quad$ Postulate 6: Around the end of primary school (or early years of secondary school;

8 about age 13), children should have the opportunity to either choose to specialize in

9 their favourite sport, or to continue in sport at a recreational level

10 This postulate focuses on the transition between childhood and adolescence as an

11 important period to specialize in one sport or stay involved in sport at a recreational

12 level. Specialization in one sport typically does not occur, nor does it need to occur,

13 before age 13 in sports where peak performance is reached in adulthood. One of the

14 most important reasons that all children should be provided with sampling opportunities

15 during childhood is from a motivational perspective. The quality of early learning

16 experiences through diversification and deliberate play during childhood develop not

17 only physical competencies, but also perceptions of competence, which in turn lead to

18 motivation for continued participation, performance, and personal development (Bruner

19 et al. 2011). Motivation theories suggest that children's perceptions of competence in

20 late childhood (ages 8-12) are largely the result of comparisons with their peers. It is

21 only at about the age of 12 or 13 that children are able to fully understand the differing

22 effects that effort, practice, and ability have on their performances (Horn and Harris

23 2002). Because children do not understand competition and sport performances the 
1 same way adults do, coaches should not overemphasize performance through deliberate

2 practice or over-organized competition during childhood. In fact, overemphasizing

3 performance can lead to early stratification of youth sport competitive levels, which

4 might perpetuate relative age effects (participation or performance advantages for

5 athletes born early in the selection year; Musch and Grondin 2001). Hancock et al.

6 (2013b) exemplified this trend discovering that Canadian youth ice hockey players

7 demonstrated relative age effects at the youngest competitive levels (age 7) where early

8 stratification begins. By introducing early stratification, deselected athletes possibly

9 experience decreases in competence, confidence, and motivation. This is despite the

10 fact that deselections might be attributed to relative age and are not indicative of

11 potential sport ability. In essence, a relative younger child's motivation to engage in

12 sport might unnecessarily be tempered by premature stratification.

13 Postulate 7: Late adolescents (around age 16) have developed the physical,

14 cognitive, social, emotional, and motor skills needed to invest their efforts into

15 highly specialized training in one sport

16 This postulate focuses on the transition to an intense period of training with the

17 sole purpose of developing elite performance in one sport. For those few athletes with

18 the talent, dedication, and potential to reach elite status, it is important to enter the

19 investment stage at the developmentally appropriate time. By about age 12, children are

20 cognitively and physically ready to participate in competitive sports; however, investing

21 in one sport requires a few more years of maturity (Patel et al 2002). In fact, sport

22 studies indicate that age 16 is an appropriate time to begin increasing deliberate practice

23 hours in one sport, and limiting involvement in other sports (Helsen et al. 1998, Côté 
1 1999, Baker et al. 2003a, Kirk and MacPhail 2003, MacPhail et al. 2003, Baker et al.

2 2005). Moreover, research in sports where specialization and investment occur before

3 age 16 (e.g., female gymnastics and figure skating) has indicated several negative

4 outcomes such as more injuries and less enjoyment (Starkes et al. 1996, Law et al.

5 2007).

The DMSP and its postulates integrate the 3Ps of sport - performance,

7 participation, and personal development - by focusing on key proximal processes

8 (deliberate play and diversification) and the environment in which the processes occur

9 (role of coaches, peers, and parents). Furthermore, the overly structured, competitive, and

10 adult-driven aspects of organized sport and deliberate practice during childhood can lead

11 to negative outcomes such as early exclusion of late-maturing athletes and the increased

12 prevalence of overuse injuries and dropout, all of which can potentially limit the talent

13 development pool for certain sports. The evidence is clear that all future expert athletes

14 need to adopt intensive, sport-specific training programs in order to be internationally

15 competitive and successful; however, these programs should only be implemented after

16 reaching adolescence. Despite this evidence, many organizations do not implement this

17 approach, possibly due to lack of awareness of the benefits of a holistic, integrated

18 approach. As such, we suggest 10 recommendations for youth sport governing bodies to

19 consider for implementation in order to integrate the 3Ps.

\section{Recommended Youth Sport Policies to Integrate the 3Ps}

21 The literature on athletes' development in sport clearly indicates that sport

22 programs for children under the age of 13 should be aligned with the specific needs of 
1 this age group. Below are 10 recommendations that should be considered in the design

2 of sport programs for children:

3 1. Regulate length of season to 3 or 4 months, with a maximum of 6 months.

42 2. Limit lengthy travel to organized competitions.

$5 \quad 3$. Introduce "grassroots" sport programs that focus on trying different sports.

64 4. Do not implement a selection process of more "talented" children until the $7 \quad$ specialization years.

8 5. Provide healthy competitive opportunities, but do not over-emphasize winning 9 and long-term outcomes such as championships.

10 6. Discourage early specialization in one sport.

11 7. Allow children to play all positions in a given sport.

12 8. Promote deliberate play within and beyond organized sport.

9. Design play and practice activities that focus on fun and short-term rewards.

$14 \quad 10$. Understand children's needs and do not "over coach.”

16 The 3Ps of sport outcomes include performance, participation, and personal

17 development. Frequently, governing bodies structure sport with the aim of achieving 18 one of the 3Ps at the expense of the others. Yet it is clear from the evidence herein that 19 sport programs can, and should, incorporate the 3Ps without sacrificing any. The keys 20 to this balance are focusing on early diversification, deliberate play, and fun (proximal 21 variables for the athletes) in order to develop intrinsic motivation, competitive spirit, and

22 lifelong participation. In doing so, youth will build a foundation for elite performance

23 (if they so choose), participation, and personal development. 
1 Some of the recommendations that were generated in this article are much in line

2 with existing sport models, such as Sport Education (e.g., Siedentop 2002b) or Teaching

3 Games for Understanding (Griffin and Butler 2005). The recommendations, however,

$4 \quad$ address larger issues not included in these pedagogical models of youth sport and

5 suggest a fundamental redesign of sport programs and a rethinking of how coaches can

6 best promote children's performance, participation, and personal development in sport.

7 The 10 evidence-based recommendations, which emerged from the DMSP and its

8 postulates, advocate policies that focus on program designs and coaching. In terms of

9 program designs, recommendations 1 to 5 propose changes to youth sport programs that

10 focus on season lengths, programing of different sports, and changes in the competition

11 structure of youth sport. Recommendations 6 to 10 are policies that concern the role of

12 coaches. Generally, recommendations related to coaching imply knowledge and

13 behaviours that focus on the relational aspect of coaching and de-emphasize the

14 technical and sport-specific aspect of coaching children.

15 The 10 recommendations, derived from the DMSP and its postulates, are well

16 supported by research and show that youth sport programs that are focused on the

17 involvement of all children in different sport contexts and rooted in play theory can have

18 long-term effects on the participation, future elite performance, and personal

19 development of athletes. The application of these 10 recommendations will require the

20 majority of adults involved in youth sport to change their traditional views and refocus

21 their efforts on engineering a youth sport structure that focuses on the elements of sport

22 that children value - a refocus that ought to be swift considering there is insufficient

23 evidence supporting the position that elite sport structures facilitate mass sport 
1 participation (Coalter 2004, Horne 2007). Rather, current evidence clearly demonstrates

2 that children's sport programs targeting play and participation in different contexts tend

3 to facilitate long-term benefits that meet the excellence and participation agenda of

4 governments around the world (Skille 2011, Comeau 2013). Global sport organizations

5 and sport governing bodies ought to immediately consider this integrative approach to

6 offer their constituents more inclusive and beneficial sport opportunities. 
2 Abbott, A., and Collins, D., 2004. Eliminating the dichotomy between theory and 3

\section{References} practice in talent identification and development: Considering the role of psychology. Journal of sports sciences, 22 (5), 395-408.

Abernethy, B., Baker, J., and Côté, J., 2005. Transfer of pattern recall skills as a contributor to the development of sport expertise. Applied cognitive psychology, 19 (6), 705-718.

Abernethy, B., Farrow, D., and Berry, J., 2003. Constraints and issues in the development of a general theory of expert perceptual-motor performance. In: J.L. Starkes and K.A. Ericsson, eds. Expert performance in sports: Advances in research on sport expertise. Champaign, IL: Human Kinetics, 349-369.

Alfermann, D., and Stambulova, N., 2007. Career transitions and career termination. In: G. Tenenbaum and R.C. Eklund, eds. Handbook of sport psychology. 3rd ed. New York: Wiley, 712-736.

Bailey, R., and Morley, D., 2006. Towards a model of talent development in physical education. Sport, education and society, 11 (3), 211-230.

Bailey, R.P., Collins, D., Ford, P.A., MacNamara, Á., Pearce, G., and Toms, M., 2010. Participant development in sport: An academic literature review. Leeds: Sports Coach UK. Commissioned report for Sports Coach UK

Baker, J., Côté, J., and Abernethy, B., 2003a. Learning from the experts: Practice activities of expert decision makers in sport. Research quarterly for exercise and sport, 74 (3), 342-347. 
1 Baker, J., Côté, J., and Abernethy, B., 2003b. Sport-specific practice and the development of expert decision-making in team ball sports. Journal of applied sport psychology, 15 (1), 12-25.

Baker, J., Côté, J., and Deakin, J., 2005. Expertise in ultraendurance triathletes early sport involvement, training structure, and the theory of deliberate practice. Journal of applied sport psychology, 17 (1), 64-78.

Balyi, I., and Hamilton, A., 2004. Long-term athlete development: Trainability in children and adolescents. Windows of opportunity. Optimal trainability. Victoria, BC: National Coaching Institute British Columbia and Advanced Training and Performance.

Berry, J., and Abernethy, B., 2009. Developmental influences on the acquisition of tactical decision-making expertise. International journal of sport psychology, 40 (4), 525-545.

Berry, J., Abernethy, B., and Côté, J., 2008. The contribution of structured activity and deliberate play to the development of expert perceptual and decision-making skill. Journal of sport \& exercise psychology, 30 (6), 685-708.

Biddle, S.J.H., 2001. Enhancing motivation in physical education. In: G.C. Roberts, ed. Advances in motivation in sport and exercise. Champaign, IL: Human Kinetics, 101-128.

Bloom, B.S., 1985. Developing talent in young people. New York: Ballantine. Bridge, M.W., and Toms, M.R., 2013. The specialising or sampling debate: A retrospective analysis of adolescent sports participation in the UK. Journal of sports sciences, 31 (1), 87-96. 
1 Bruner, M.W., Erickson, K., McFadden, K.K., and Côté, J., 2009. Tracing the origins of athlete development models in sport: A citation path network analysis. International review of sport and exercise psychology, 2 (1), 23-37.

Bruner, M.W., Erickson, K., Wilson, B., and Côté, J., 2010. An appraisal of athlete development models through citation network analysis. Psychology of sport and exercise, 11 (2), 133-139.

Bruner, M.W., Strachan, L., and Côté, J., 2011. Developmental transitions in sport. In: I. Stafford, ed. Coaching children in sport. London: Routledge, 227-239.

Busseri, M.A., Rose-Krasnor, L., Willoughby, T., and Chalmers, H., 2006. A longitudinal examination of breadth and intensity of youth activity involvement and successful development. Developmental psychology, 42 (6), 1313-1326.

Carlson, R.C., 1988. The socialization of elite tennis players in Sweden: An analysis of players’ backgrounds and development. Sociology of sport journal, 5 (3), 241256.

Coalter, F., 2004. Stuck in the blocks? A sustainable sporting legacy. In: A. Vigor and M. Mean, eds. After the gold rush: The London Olympics. London: Institute of Public Policy Research/Demos, 91-108.

Coalter, F., 2007. Sport a wider social role: Whose keeping the score? London: Routledge.

Coalter, F., 2010. The politics of sport-for-development: Limited focus programmes and broad gauge problems. International review for the sociology of sport, 45 (3), 295-314. 
1 Collins, M., 2010. From 'sport for good' to 'sport for sport's sake' - not a good move 2 for sports development in England? International journal of sport policy and politics, 2 (3), 367-379.

4 Comeau, G.S., 2013. The evolution of Canadian sport policy. International journal of

6 Côté, J., 1999. The influence of the family in the development of talent in sport. The $7 \quad$ sport psychologist, 13 (4), 395-417.

8 Côté, J., 2009. The road to continued sport participation and excellence. In: E. Tsung-

9 Min Hung, R. Lidor, and D. Hackfort, eds. Psychology of sport excellence. Morgantown, WV: Fitness Information Technology, 97-104.

11 Côté, J., and Abernethy, B., 2012. A developmental approach to sport expertise. In: S. Murphy, ed. The Oxford handbook of sport and performance psychology. New

14 Côté, J., Baker, J., and Abernethy, B., 2007b. Practice and play in the development of sport expertise. In: G. Tenenbaum and R.C. Eklund, eds. Handbook of sport psychology. 3rd ed. New York: Wiley, 184-202.

17 Côté, J., Coakley, C., and Bruner, M.W., 2011. Children’s talent development in sport: Effectiveness or efficiency? In: S. Dagkas and K. Armour, eds. Inclusion and exclusion through youth sport. London: Routledge, 172-185.

Côté, J., Ericsson, K.A., and Law, M.P., 2005. Tracing the development of athletes using retrospective interview methods: A proposed interview and validation procedure for reported information. Journal of applied sport psychology, 17 (1), $1-19$. 
1 Côté, J., Lidor, R., and Hackfort, D., 2009. ISSP position stand: To sample or to

2 specialize? Seven postulates about youth sport activities that lead to continued

3 participation and elite performance. International journal of sport and exercise

$4 \quad$ psychology, 9 (1), 7-17.

5 Côté, J., Strachan, L., and Fraser-Thomas, J., 2007a. Participation, personal

6 development, and performance through youth sport. In: N.L. Holt, ed. Positive

$7 \quad$ youth development through sport. London: Routledge, 34-45.

8 Coyle, D., 2009. The talent code: Greatness isn't born, it's grown. And here's how.

$9 \quad$ New York: Random House.

10 Danish, S.J., Fazio, R.J., Nellen, V.C., and Owens, S.S., 2002. Teaching life skills

11 through sport: Community-based programs to enhance adolescent development.

12 In: J.L. Van Raalte, ed. Exploring sport and exercise psychology. 2nd ed.

13 Washington: American Psychological Association, 269-288.

14 Danish, S., Petitpas, A., and Hale, B., 1993. Life development intervention for athletes:

15 Life skills through sport. The counselling psychologist, 21 (3), 352-385.

16 Deci, E.L., and Ryan, R.M., 1985. Intrinsic motivation and self-determination in human

17 behavior. New York: Plenum

18 Ericsson, K.A., Krampe, R.T., and Tesch-Römer, C., 1993. The role of deliberate

19 practice in the acquisition of expert performance. Psychological review, 100 (3),

$20 \quad 363-406$.

21

22

23 
1 Ewing, M.E., and Seefeldt, V., 1996. Patterns of participation and attrition in American

2 agency sponsored youth sports. In: F.L. Smoll and R.E. Smith, eds. Children and youth in sport: A biopsychosocial perspective. Dubuque, IA: Brown and Benchmark, 31-45.

Ford, P.R., Ward, P., Hodges, N.J., and Williams, A.M., 2009. The role of deliberate practice and play in career progression in sport: The early engagement hypothesis. High ability studies, 20 (1), 65-75.

Ford, P.R., et al., 2011. The long-term athlete development model: Physiological evidence and application. Journal of sports sciences, 29 (4), 389-402.

Ford, P.R., and Williams, A.M., 2012. The developmental activities engaged in by elite youth soccer players who progressed to professional status compared to those who did not. Psychology of sport and exercise, 13 (3), 349-252.

Fraser-Thomas, J., and Côté, J., 2009. Understanding adolescents’ positive and negative developmental experiences in sport. The sport psychologist, 23 (1), 3-23.

Fraser-Thomas, J., Côté, J., and Deakin, J., 2005. Youth sport programs: An avenue to foster positive youth development. Physical education and sport pedagogy, 10 (1), 19-40.

Fraser-Thomas, J., Côté, J., and Deakin, J., 2008a. Understanding dropout and prolonged engagement in adolescent competitive sport. Psychology of sport and exercise, 9 (5), 645-662.

Fraser-Thomas, J., Côté, J., and Deakin, J., 2008b. Examining adolescent sport dropout and prolonged engagement from a developmental perspective. Journal of applied sport psychology, 20 (3), 318-333. 
1 Fredricks, J.A., and Eccles, J.S., 2006. Extracurricular involvement and adolescent

2 adjustment: Impact of duration, number of activities, and breadth of participation. Applied developmental science, 10 (3), 132-146.

4 Fry, M.D., 2001. The development of motivation in children. In: G.C. Roberts, ed. Advances in motivation in sport and exercise. Champaign, IL: Human Kinetics, $51-78$.

7 Gladwell, M., 2008. Outliers: The story of success. New York: Little, Brown and Company.

9 Gould, D., 1987. Understanding attrition in children's sport. In: D. Gould and M.R. Weiss, eds. Advances in pediatric sport sciences. Volume 2: Behavioral issues. Champaign, IL: Human Kinetics, 401-411.

Gould, D., Udry, E., Tuffey, S., and Loehr, J., 1996. Burnout in competitive junior tennis players: I. A quantitative psychological assessment. The sport psychologist, 10 (4), 322-340.

Griffin, L.L., and Butler, J.I., 2005. Teaching games for understanding: Theory, research, and practice. Champaign, IL: Human Kinetics.

17 Gulbin, J.P., Oldenziel, K.E., Weissensteiner, J.R., and Gagné, F., 2010. A look through the rear view mirror: Developmental experiences and insights of high performance athletes. Talent development \& excellence, 2 (2), 149-164. 630-637. 
1 Hancock, D.J., Ste-Marie, D.M., and Young, B.W., 2013b. The relative age effect in male youth ice hockey: An inference regarding coach and parental influences. Research quarterly for exercise and sport, 84 (1), 126-130.

Hellion, D., and Walsh, D., 2002. Responsibility-based youth programs evaluation: Investigating the investigations. Quest, 54 (4), 292-307.

Helsen, W.F., Starkes, J.L., and Hodges, N.J., 1998. Team sports and the theory of deliberate practice. Journal of sport \& exercise psychology, 20 (1), 12-34.

Hill, G.M., 1993. Youth participation of professional baseball players. Sociology of sport journal, 10 (1), 107-114.

Hodge, T., and Deakin, J., 1998. Deliberate practice and expertise in the martial arts: The role of context in motor recall. Journal of sport \& exercise psychology, 20 (3), 260279.

Hodges, N.J., and Starkes, J.L., 1996. Wrestling with the nature of expertise: A sport specific test of Ericsson, Krampe and Tesch-Römer’s (1993) theory of deliberate practice. International journal of sport psychology, 27 (4), 400-424.

Horn, T.S. and Harris, A., 2002. Perceived competence in young athletes: Research findings and recommendations for coaches and parents. In: F.L. Smoll and R.E. Smith, eds. Children and youth in sport. A biopsychosocial perspective. 2nd ed. Dubuque, IA: Kendall Hunt, 435-464.

Horne, J., 2007. The ‘four knowns’ of sports mega-events. Leisure studies, 26 (1), 8196. 
1 Janssen, I., and LeBlanc, A.G., 2010. Systematic review of the health benefits of physical activity and fitness in school-aged children and youth. International journal of behavioral nutrition and physical activity, 7, doi: 10.1186/1479-58687-40.

Kelley, B., and Carchia, C., 2013. "Hey, data data - swing!” The hidden demographics of youth sports. Available from http://espn.go.com/espn/story/_/id/ 9469252/hidden-demographics-youth-sports-espn-magazine [Accessed 10 October 2013].

Kirk, D., and Macphail, A., 2003. Social positioning and the construction of a youth sports club. International review for the sociology of sport, 38 (1), 23-44.

Law, M.P., Côté, J., and Ericsson, K.A., 2007. Characteristics of expert development in rhythmic gymnastics: A retrospective study. International journal of sport and exercise psychology, 5 (1), 82-103.

Leite, N., and Sampaio, J., 2012. Early sport involvement in young Portuguese basketball players. Perceptual and Motor Skills, 111 (3), 669-680.

MacDonald, D.J., Cheung, M., Côté, J., and Abernethy, B., 2009. Place but not date of birth influences the development and emergence of athletic talent in American football. Journal of applied sport psychology, 21 (1), 80-90.

Macphail, A., Gorely, T., and Kirk, D., 2003. Young people’s socialisation into sport: A case study of an athletic club. Sport, education and society, 8 (2), 251-268.

Malina, R.M., 2013. Motor development and performance. In: J. Côté and R. Lidor, eds. Conditions of children's talent development in sport. Morgantown, WV: Fitness Information Technology, 61-84. 
1 Memmert, D., Baker, J., and Bertsch, C., 2010. Play and practice in the development of 2 sport-specific creativity in team ball sports. High ability studies, 21 (1), 3-18.

3 Musch, J., and Grondin, S., 2001. Unequal competition as an impediment to personal 4 development: A review of the relative age effect in sport. Developmental review, $21(2), 147-167$.

6 National Research Council and Institute of Medicine., 2002. Community programs to $7 \quad$ promote community development. Washington, DC: National Academy Press.

8 Parcels, J., 2002. Chances of making it in pro hockey. Ontario Minor Hockey

9 Association. Available from http://www.omha.net/flash.asp?page_id=242 [Accessed 7 January 2013].

Patel, D.R., Pratt, H.D., and Greydanus, D.E., 2002. Pediatric neurodevelopment and sports participation: When are children ready to play sports? Pediatric clinics of North America, 49 (6), 505-531.

Pearson, D., Naughton, G., and Torode, M., 2006. Predictability of physiological testing and the role of maturation in talent identification for adolescent team sports. Journal of science and medicine in sport, 9 (4), 277-287.

Petitpas, A.J., Van Raalte, J.L., Cornelius, A., and Presbrey, J., 2004. A life skills development program for high school student-athletes. The journal of primary prevention, 24 (3), 325-334.

Robertson-Wilson, J., Baker, J., Derbinshyre, E., and Côté, J., 2003. Childhood sport involvement in active and inactive adult females. AVANTE, 9 (1), 1-8. 
1 Rose-Krasnor, L., Busseri, M., Willoughby, T., and Chalmers, H., 2006. Breadth and intensity of youth activity involvement as contexts for positive development. Journal of youth and adolescence, 35 (3), 365-379.

4 Ryan, R.M., and Deci, E.L., 2000. Self-determination theory and the facilitation of intrinsic motivation, social development, and well being. American psychologist, 55 (1), 68-78.

7 Salmela, J.H., 1994. Phases and transitions across sports career. In: D. Hackfort, ed. Psycho-social issues and interventions in elite sport. Frankfurt: Lang, 11-28.

9 Siedentop, D., 2002a. Junior sport and the evolution of sport cultures. Journal of teaching in physical education, 21 (4), 392-401.

11 Siedentop, D., 2002b. Sport education: A retrospective. Journal of teaching in physical education, 21 (4), 409-418.

Skille, E.Å., 2011. Sport for all in Scandinavia: Sport policy and participation in Norway, Sweden and Denmark. International journal of sport policy and politics, 3 (3), 327-339.

Soberlak, P., and Côté, J., 2003. The developmental activities of elite ice hockey players. Journal of applied sport psychology, 15 (1), 41-49.

Stambulova, N., 1994. Developmental sports career investigations in Russia: A postperestroika analysis. The sport psychologist, 8 (2), 221-237.

20 Starkes, J.L., Deakin, J., Allard, F., Hodges, N.J., and Hayes, A., 1996. Deliberate practice in sports: What is it anyway? In: K.A. Ericsson, ed. The road to excellence: The acquisition of expert performance in the arts and sciences, sports, and games. Mahwah, NJ: Erlbaum, 81-106. 
1 Strachan, L., Côté, J., and Deakin, J., 2009. “Specializers” versus “samplers” in youth

4 Strachan, L., Côté, J., and Deakin, J., 2011. A new view: Exploring positive youth 5 sport: Comparing experiences and outcomes. The sport psychologist, 23 (1), 7792. development in elite sport contexts. Qualitative research in sport, exercise, and health, 3 (1), 9-32.

Surya, M., Bruner, M.W., MacDonald, D.J., and Côté, J., 2012. A comparison of developmental activities of elite athletes born in large and small cities. Physical and health education academic journal, 4 (1), 1-8.

Treasure, D.C., 2001. Enhancing young people's motivation in youth sport: An achievement goal approach. In: G.C. Roberts, ed. Advances in motivation in sport and exercise. Champaign, IL: Human Kinetics, 79-100.

Turnnidge, J., Hancock, D.J., and Côté, J. in press. Positive youth development from sport to life: Explicit or implicit transfers? Quest.

Vaeyens, R., Gullich, A., Warr, C.R., and Philippaerts, R., 2009. Talent identification and promotion programmes of Olympic athletes. Journal of sports sciences, 27 (13), 1367-1380.

Wall, M., and Côté, J., 2007. Developmental activities that lead to drop out and investment in sport. Physical education and sport pedagogy, 12 (1), 77-87.

Weiss, M.R., Stuntz, C.P., Bhalla, J.A., Bolter, N.D., and Price, M.S., 2013. 'More than a game': Impact of the First Tee life skills programme on positive youth development: Project introduction and year 1 findings. Qualitative research in sport, exercise, and health, 5 (2), 214-244. 
1 Wilkes, S., and Côté, J., 2007. A sampling environment to promote diverse

2 relationships and continued involvement in sport. Paper presented at the European federation of sport psychology, September 2007 Halkidiki, Greece.

4 Wright, A.D., and Côté, J., 2003. A retrospective analysis of leadership development 5

6 Wylleman, P., and Lavallee, D., 2004. A developmental perspective on transitions faced $7 \quad$ by athletes. In: M.R. Weiss, ed. Developmental sport and exercise psychology: A

8 lifespan perspective. Morgantown, WV: Fitness Information Technology, 5079 527. 